\title{
INTENSITAS BISING DAN AMBANG DENGAR PADA PEKERJA RUMAH KAYU DI KELURAHAN WOLIAN I DAN II KOTA TOMOHON
}

\author{
Ivanna S.O Mamesah ${ }^{1)}$, Bongakaraeng ${ }^{2)}$, Suwarja ${ }^{3)}$ \\ ${ }^{1)}$ Dinas Kesehatan Kota Tomohon \\ ${ }^{2,3)}$ Jurusan Kesehatan Lingkungan Poltekkes Kemenkes Manado \\ Email : seidy.mamesah@yahoo.com
}

\begin{abstract}
Noise affects health, which can cause damage to the auditory sense to deafness. The purpose of this study was to determine the effect of noise intensity on the hearing threshold in wooden house workers in Wolian I and II Kelurahan Tomohon City. This type of research was an analytic observational study with a cross sectional study design. The results of the calculation of sample size in the study amounted to 34 workers. The results of processing and analysis of data bivariate using the test chi square showed that there was a significant relationship between noise and hearing threshold of wooden home workers, there was a significant relationship between length of work and disturbances. thresholdHeard wooden house workers, who obtained $p=0.031$, there was no relationship between the age of the respondents with the disturbance of the threshold with the wooden house workers in the Woloan I and II Villages of Tomohon City, who obtained $p=0.745$. Suggestion, for companies making wooden houses as input material so that they can provide personal protective equipment in the form of caps / earplugs for workers so that occupational diseases such as hearing loss can be avoided
\end{abstract}

Keywords : Noisy, hearing threshold, wooden house

\begin{abstract}
Abstrak. Kebisingan mempengaruhi kesehatan, antara lain dapat menyebabkan kerusakan pada indera pendengaran sampai kepada ketulian. Tujuan penelitian ini yaitu untuk mengetahui pengaruh Intensitas kebisingan terhadap ambang dengar pada pekerja rumah kayu di Kelurahan Wolian I dan II Kota Tomohon.Jenis penelitian ini merupakan studi observasional analitik dengan rancangan cross sectional study. Hasil perhitungan besar sampel dalam penelitian sebesar 34 orang tenaga kerja.Hasil pengolahan dan analisis data secara bivariat dengan menggunakan uji chi square mendapatkan hasil yaitu terdapat hubungan yang bermakna antara kebisingan dengan ambang dengar pekerja rumah kayu, terdapat hubungan yang bermakna antara lama kerja dengan ganguan ambang dengar pekerja rumah kayu, yang memperoleh nilai $p=0,031$, tidak terdapat hubungan antara umur responden dengan gangguan ambang dengan pekerja rumah kayu di Kelurahan Woloan I dan II Kota Tomohon, yang memperoleh nilai $p=0,745$. Saran, bagi perusahaan pembuatan rumah kayu sebagai bahan masukan agar dapat menyediakan alat pelindung diri berupa tutup/sumbat telinga bagi pekerja sehingga penyakit akibat kerja berupa gangguan pendengaran dapat dihindari
\end{abstract}

Kata Kunci : Bising, ambang dengar, rumah kayu

Kasus kebisingan dilingkungan sering terjadi, dampak yang dirasakan oleh masyarakat bermacam-macam, mulai dari tidak dapat mendengar radio/TV/percakapan secara wajar, tidak dapat tidur pada waktunya, sulit berkonsentrasi sampai gangguan psikologis lain, sebagian dari mereka berani melakukan protes, sebagian hanya bercerita kesana kemari dan sebagian diredam dalam hati meyerah pada keadaan, yang sebenarnya tidak wajar. Semua itu merupakan gangguan kesehatan (Heru S, dkk. 2008).

Penggunaan mesin yang kurang tepat dan ceroboh akan dapat menimbulkan kecelakaan pada tenaga kerja, bahkan kecacatan. Salah satu efek negatif yang ditimbulkan dari penggunaan mesin dalan indusrti yaitu suara bising dan bisa berdampak buruk bagi derajat kesehatan tenaga kerja, khususnya pada indra pendengaran (Darmawan dan Mulyono, 2014).

Tempat pembuatan rumah kayu di daerah Kota Tomohon berlokasi di Kelurahan Woloan I dan IIKecamatan. Tomohon Barat Kota Tomohon yang beroperasi sejak tahun 1942. Usahapembuatan rumah kayu berbentuk CV dan UD dan menjadi tempat penelitian mempekerjakan kurang lebih 58 orang tenaga kerja dan seluruh tenaga kerja bekerja selama 8 jam sehari dan akan lebih jika lembur serta tanpa sistem siff . Alat yang digunakan dalam aktifitas usaha pembuatan rumah kayu ini adalah mesin Somil dalam proses pemotongan serta 
penyerutan kayu, dimana kegiatan ini menimbulkan dampak bising bagi pekerja yang dapat mengganggu kesehatan.

Hasil wawancara denganbeberapa pekerjarumah kayu yang ada di Kelurahan woloan I dan II mengeluhkan merasa tidak nyaman dengan bunyi yang ditimbulkan oleh mesin somil dan rata-rata pekerja tidak menggunakan APD dalam hal ini alat pelindung telinga pada saat bekerja. Hal ini jika berlangsung secara terus menerus dampaknya dapat menurunkan konsentrasi, kelelahan, gangguan komunikasi. Dalam jangka waktu pendek gangguan ini tidak sampai menyebabkan kerusakan fisiologis pada sistem pendengaran manusia, tetapi dalam jangka panjang dapat mengakibatkan menurunnya tingkat ambang pendengaran manusia serta gangguan psikologis pekerja (Tjan, dkk. 2013). Tujuan penelitian ini yaitu untuk mengetahui pengaruh intensitas kebisingan terhadap ambang dengar pada pekerja rumah kayu di Kelurahan Wolian I dan IIKota Tomohon.

\section{Metode}

Jenis penelitian ini adalah penelitian survey analitik dengan rancangancross sectionalstudy yaiturancangan penelitian yang mengetahui antara faktor resiko paparan dengan kasus penyakit (Hidayat, 2011). Penggunaan jenis penelitian ini yaitu untuk mengetahui adanya pengaruh intensitas kebisingan terhadap ambang dengar pada pekerja rumah kayu di Kelurahan Woloan I dan II Kota Tomohon. Variabel dama penelitian ini yaitu variabel terikat atau dependen dalam penelitian ini adalah
Ambang Dengar dan variabel bebas atau Independen adalah Intensitas Kebisingan.

Populasi dalam penelitian adalah 58 pekerja rumah kayu di Kelurahan Woloan I dan II Kota Tomohon.Sampel dalam penelitian ini adalah 34 pekerja rumah Kayudi Kelurahan Woloan I dan II Kota Tomohonyang bersedia sebagai responden. Hasil penelitian dianalisissecara univariat bertujuan untuk mendeskripsikan karakteristik setiap variabel penelitian, dan analisisbivariat dilakukan terhadap dua variabel yang diduga berhubungan yang dianalisis dengan uji chi square.

\section{Hasil}

1. Hasil Pengukuran Intensitas Kebisingan

a. Pengukuran Intensitas Kebisingan di CV. Gratia Magna

Pengukuran intensitas kebisingan dilakukan 3 kali yaitu pada pagi hari mulai pukul 09.00 sampai selesai, pengukuran siang hari mulai pukul 13.00 sampai selesai dan pengukuran sore hari pukul 15.00 sampai selesai. Masing-masing titik membutuhkan waktu 15 menit.

Hasil pengukuran intensitas kebisingan di tempat penelitian untuk lokasi pengukuran CV. Gratia Magna rata-rata pengukuran tidak melebih dari batas yang telah ditentukan yaitu $\leq 85$ dB memenuhi syarat. Rata-rata pengukuran untuk pagi hari $=83,171$ $\mathrm{dB}$, siang hari $=82,648 \mathrm{~dB}$ dan pengukuran sore hari $=82,196 \mathrm{~dB}$. Hasil pengukuran dapat ditunjukan pada tabel 1 di bawah ini :

Tabel 1. Intensitas Kebisingan pada CV. Gratia Magna

\begin{tabular}{cccc}
\hline \multirow{2}{*}{ Titik Lokasi } & \multicolumn{3}{c}{ Waktu Pengukuran } \\
\cline { 2 - 4 } & Pagi & Siang & Sore \\
\hline Titik 1 & 83.648 & 82.558 & 82.276 \\
Titik 2 & 83.413 & 82.889 & 82.002 \\
Titik 3 & 82.695 & 82.989 & 81.852 \\
Titik 4 & 82.452 & 82.285 & 81.889 \\
Titik 5 & 82.476 & 82.392 & 81.967 \\
Titik 6 & 83.338 & 82.678 & 82.590 \\
Titik 7 & 84.176 & 82.743 & 82.798 \\
\hline Rata-Rata & 83.171 & 82.648 & 82.196 \\
\hline
\end{tabular}


Fluktuasi pengukuran intensitas kebisingan dari titik 1 sampai pada titik 7 pada

CV Gratia Magna, dapat ditunjukan pada grafik 1 di bawah ini :

Grafik 1. Fluktiasi Intensitas Kebisingan Pada CV. Gratia Magna

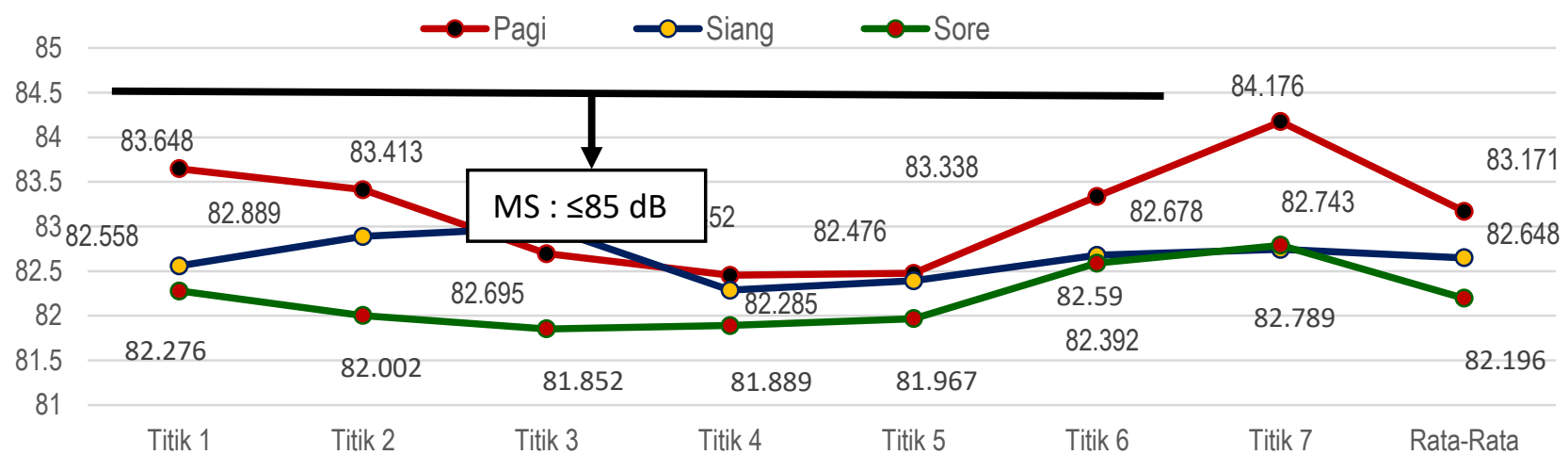

Hasil pengukuran pada titik 1 sampai dengan titik 7, tidak melebihi nilai ambang batas (NAB) yang dipersyaratkan yaitu $\leq 85 \mathrm{~dB}$, dimana untuk pengukuran pada pagi hari paling rendah $82,452 \mathrm{~dB}$ dan paling tinggi $=84,176 \mathrm{~dB}$.

b. Pengukuran Intensitas Kebisingan di CV. Yudi

Tabel 2. Intensitas Kebisingan pada CV. Yudi
Rata-rata hasil pengukuran intensitas kebisingan di CV Yudi, untuk pengukuran pagi hari $=84,973 \mathrm{~dB}$, rerata pengukuran pada siang hari $=83,938 \mathrm{~dB}$ dan pada sore hari $=86,474 \mathrm{~dB}$. Rerata pengukuran pada sore hari melebihi NAB yang telah di tentukan yaitu $>85 \mathrm{~dB}$. Untuk lebih jelanya dapat ditunjukan pada tabel 2 di bawah ini :

\begin{tabular}{cccc}
\hline \multirow{2}{*}{ Titik Lokasi } & \multicolumn{3}{c}{ Waktu Pengukuran } \\
\cline { 2 - 4 } & Pagi & Siang & Sore \\
\hline Titik 1 & 85.454 & 84.314 & 86.081 \\
Titik 2 & 85.199 & 84.003 & 86.516 \\
Titik 3 & 84.911 & 83.772 & 86.799 \\
Titik 4 & 84.327 & 83.663 & 86.501 \\
\hline Rata-Rata & 84.973 & 83.938 & 86.474 \\
\hline Fluktuasi pengukuran intensitas & pada CV Yudi, dapat ditunjukan pada grafik \\
kebisingan dari titik 1 sampai pada titik 4 & 2 di bawah ini :
\end{tabular}

Grafik 2. Fluktiasi Intensitas Kebisingan di CV. Yudi

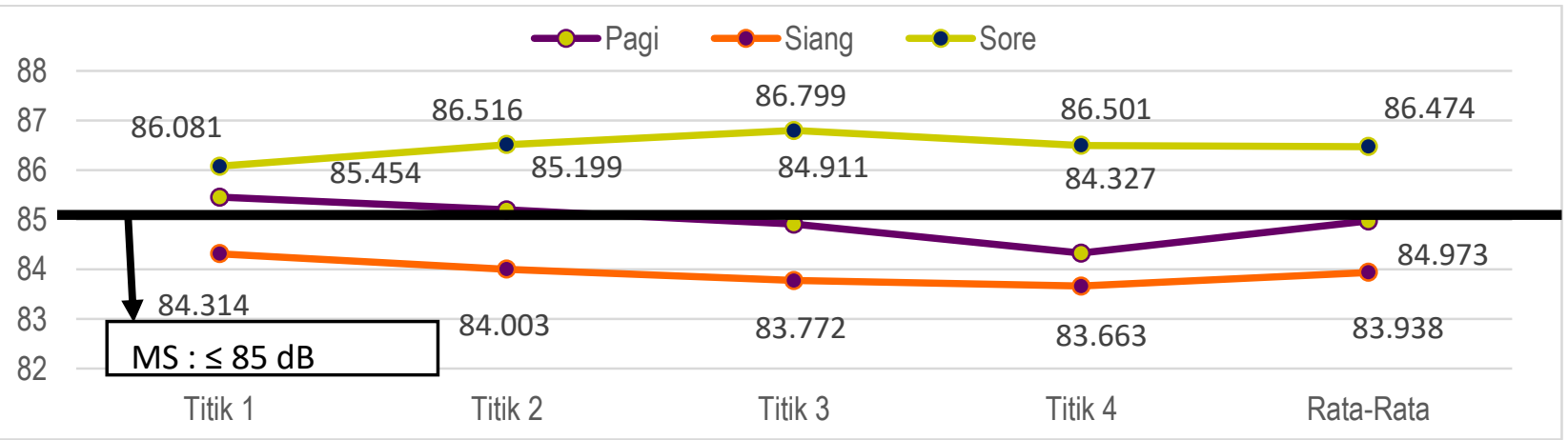


Garifk 2 menjelaskan bahwa hasil pengukuran pada pagi hari untuk titik 1 dan titik 2 sudah melebihi NAB yang dipersyaratkan $(85 \mathrm{~dB})$ dengan hasil pengukuran $=85,199 \mathrm{~dB}-85,454 \mathrm{~dB}$. Untuk pengukuran pada titik 3 dan titik 4 tidak melebihi NAB $(85 \mathrm{~dB})$, dengan hasil pengukuran $=84,327 \mathrm{~dB}-84,911 \mathrm{~dB}$. Hasil pengukuran pada siang hari tidak melebihi NAB yang telah dipersyaratkan, dengan hasil yaitu paling rendah $=83,663 \mathrm{~dB}$ dan paling tinggi yaitu 84,314 dB.

Hasil pengukuran pada sore hari untuk titik 1 sampai dengan titik 4 sudah melebihi NAB yaitu $86,081 \mathrm{~dB}$ sampai dengan 86,799 dB.

c. Pengukuran Intensitas Kebisingan di UD. Ares

Hasil pengukuran intensitas kebisingan di UD. Ares dapat ditunjukan pada tabel 3 di bawah ini :

Tabel 3. Intensitas Kebisingan pada UD. Ares

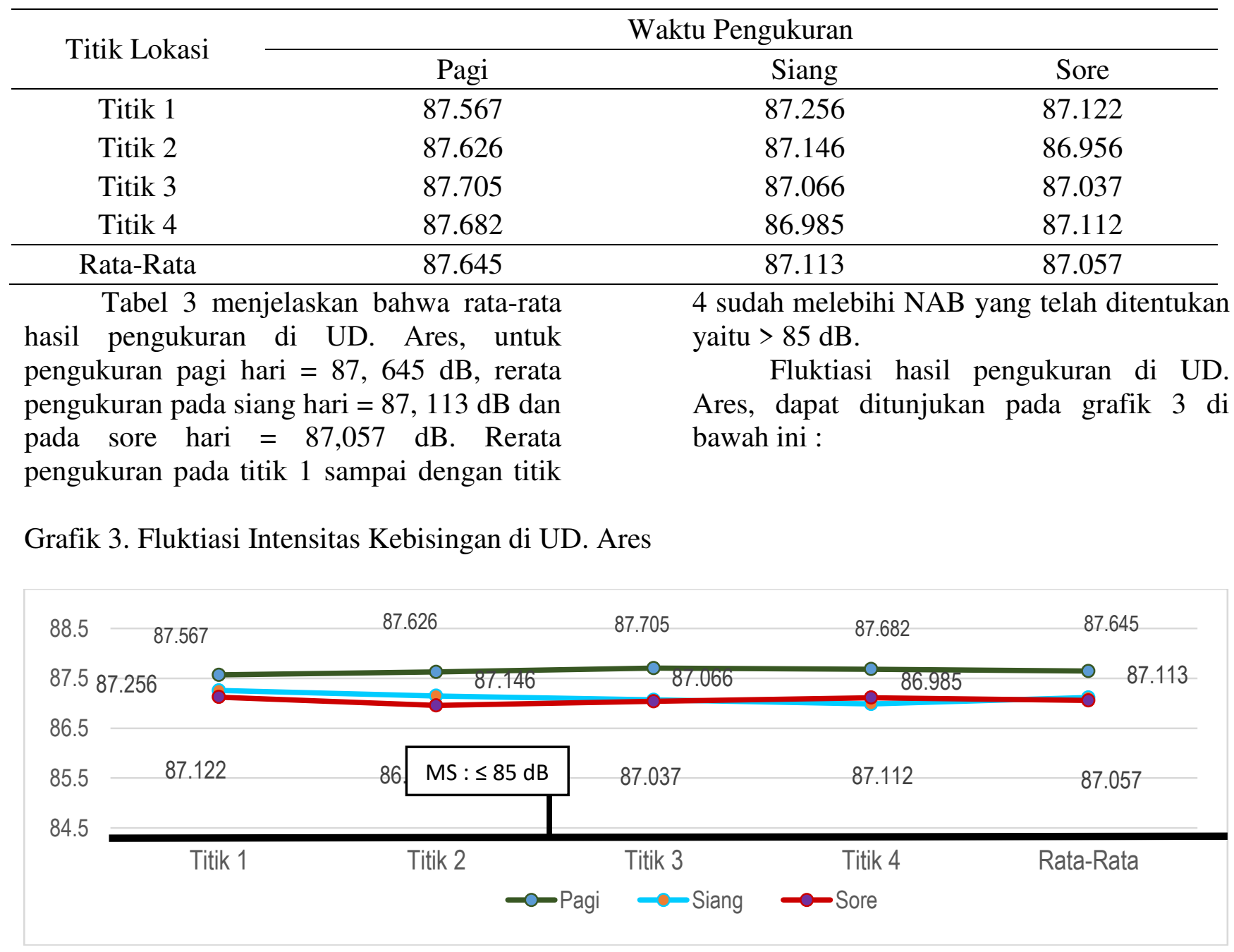

Berdasarkan garifk 3, hasil pengukuran pada pagi hari untuk titik 1 sampai titik 4 sudah melebihi NAB yang dipersyaratkan (85dB) dengan hasil pengukuran yaitu, pada pagi hari tingkat kebisingan $=87,567 \mathrm{~dB}-87,705 \mathrm{~dB}$. Pengukuran pada siang hari $=86,985 \mathrm{~dB}-$
87, $256 \mathrm{~dB}$. Hasil pengukuran pada sore hari $=86,956 \mathrm{~dB}-87,122 \mathrm{~dB}$.

2. Hasil analisis bivariat

a. Hubungan Umur dengan Ambang Dengar

Hasil analisis data untuk hubungan umur dengan ambang dengar dimana untuk umur 17 - 25 tahun sebanyak 6 orang $(17,6 \%)$, yang mengalami gangguan ambang 
dengar 1 orang responden $(2,9 \%)$ dan tidak mengalami gangguan ambang dengan / pendengaran normal sebanyal 5 orang $(14,7 \%)$. Responden dengan umur 26 - 35 tahun sebanyak 14 orang $(41,2 \%)$, yang mengalami gangguan ambang dengar sebanyal 5 responden $(14,7 \%)$ dan responden yang mempunyai pendengaran normal sebanyak 9 orang $(26,5 \%)$. Untuk responden dengan umur $36-45$ tahun sebanyak 9 orang $(26,5 \%)$, yang mengalami gangguan pendengaran sebanyak 2 orang $(5,9 \%)$ dan responden dengan pendengaran yang normal sebanyak 7 orang $(20,6 \%)$ dan untuk responden dengan umur $>45$ tahun sebanyak 5 orang, yang mengalami gangguan pendengaran sebanyak 2 orang $(5,9 \%)$ dan responden dengan pendengaran yang normal sebanyak 3 orang $(8,8 \%)$. Untuk lebih jelasnya dapat ditunjukan pada tabel 4 di bawah ini :

Tabel 4. Hubungan Umur Reponden dengan Ambang Dengar

\begin{tabular}{|c|c|c|c|c|c|c|c|}
\hline \multirow{3}{*}{ Umur } & \multicolumn{4}{|c|}{ Ambang Dengar } & \multirow{3}{*}{$\mathrm{N}$} & \multirow{3}{*}{$\%$} & \multirow{3}{*}{$p$-value } \\
\hline & \multicolumn{2}{|c|}{ Tuli Ringan } & \multicolumn{2}{|c|}{ Normal } & & & \\
\hline & $\mathrm{n}$ & $\%$ & $\mathrm{n}$ & $\%$ & & & \\
\hline $17-25$ Thn & 1 & 2.9 & 5 & 14.7 & 6 & 17.6 & \\
\hline $26-35$ Thn & 5 & 14.7 & 9 & 26.5 & 14 & 41.2 & \\
\hline 36 - 45 Thn & 2 & 5.9 & 7 & 20.6 & 9 & 26.5 & 0,745 \\
\hline$>45 \mathrm{Thn}$ & 2 & 5.9 & 3 & 8.8 & 5 & 14.7 & \\
\hline Total & 10 & 29.4 & 24 & 70.6 & 34 & 100 & \\
\hline
\end{tabular}

Tabel 4 menjelaskan berdasarkan hasil analisis secara statistik membuktikan bahwa tidak ada hubungan antara umur responden dengan gangguan ambang dengan, yang memperoleh nilai $p=0,745$.

b. Hubungan Lama Kerja dengan Gangguan Pendengaran.

Hasil analisis data untuk hubungan lama kerja dengan gangguan ambang dengar dari tenaga kerja yaitu paling banyak adalah responden dengan lama kerja $<10$ tahun sebanyak 21 orang $(61,8 \%)$ yang mengalami gangguan ambang dengan sebanyak 9 orang $(26,5 \%)$ dengan kategori tuli ringan dan responden dengan pendengaran normal sebanyak 12 orang $(35,3 \%)$. Responden dengan lama kerja > 10 tahun sebanyak 13 orang $(38,2 \%$ yang mengalami gangguan ambang dengar dengan keluahan tuli ringan sebanyak 1 orang $(2,9 \%)$ dan responden dengan pendengaran yang normal sebanyak 12 orang $(35,3 \%)$. Untuk lebih jelasnya dapat ditunjukan pada tabel 5 di bawah ini :

Tabel 5. Hubungan Lama Kerja dengan Gangguan Ambang Dengar

\begin{tabular}{|c|c|c|c|c|c|c|c|}
\hline \multirow{3}{*}{ Lama Kerja } & \multicolumn{4}{|c|}{ Ambang Dengar } & \multirow{3}{*}{$\mathrm{N}$} & \multirow{3}{*}{$\%$} & \multirow{3}{*}{$p$-value } \\
\hline & \multicolumn{2}{|c|}{ Tuli Ringan } & \multicolumn{2}{|c|}{ Normal } & & & \\
\hline & $\mathrm{n}$ & $\%$ & $\mathrm{n}$ & $\%$ & & & \\
\hline$>10$ tahun & 1 & 2.9 & 12 & 35.3 & 13 & 38.2 & \\
\hline$<10$ tahun & 9 & 26.5 & 12 & 35.3 & 21 & 61.8 & 0,031 \\
\hline Total & 10 & 29.4 & 24 & 70.6 & 34 & 100 & \\
\hline
\end{tabular}

Tabel 8 mejelaskan untuk hasil analisis secara statistik membuktikan terdapat hubungan yang bermakna antara lama kerja dengan ganguan ambang dengar pekrja, yang memperoleh nilai $p=0,031$.

\section{Pembahasan}

1. Hasil Pengukuran Intensitas Kebisingan dengan Ambang Dengan 
Pengukuran intensitas kebisingan di CV. Gratia Magna fluktuasi pengukuran intensitas kebisingan pada titik 1 sampai dengan titik 7, tidak melebihi nilai ambang batas (NAB) yang dipersyaratkan yaitu 85 $\mathrm{dB}$, dimana untuk pengukuran pada pagi hari paling rendah $82,452 \mathrm{~dB}$ dan paling tinggi $=$ 84,176 dB, (Tabel 4 ).

Pengukuran intensitas kebisingan di $\mathrm{CV}$ Yudi dengan rata-rata hasil pengukuran pada pagi hari $=84,073 \mathrm{~dB}$, rerata pengukuran pada siang hari $=83,938 \mathrm{~dB}$ dan pada sore hari $=86,474 \mathrm{~dB}$. Rerata pengukuran pada Sore hari melebihi NAB yang telah di tentukan yaitu $>85 \mathrm{~dB}$, (Tabel $5)$.

Dari hasil pengukuran pada CV. Yudi ini terdapat hasil yang berbeda yaitu pada pengukuran pagi dan siang hari menunjukan tidak melebihi nilai ambang batas (NAB) yang dipersyaratkan yaitu $85 \mathrm{~dB}$, sedangkan pada pengukuran sore hari didapat hasil yang melebihi nilai ambang batas (NAB) yang dipersyaratkan yaitu $\geq 85 \mathrm{~dB}$. Perbedaan hasil ini dapat disebabkan karena faktor lingkungan sekitar seperti arah angin. Untuk diketahui bahwa tempat pembuatanrumah kayu ini berupa banguan terbuka tanpa dinding hanya tertutup pada bagian atap. Sumber kebisingan yang ada dihasilkan dari mesin somil terdiri dari mesin skap, gergaji potong dan gergaji iris. Penempatan dari masing-masing alat ini antara mesin yang satu dengan yang lain letaknya tidak lebih 3 meter.

Sedangkan hasil pengukuran intensitas kebisingan di UD. Ares pada pengukuran pagi, siang dan pada sore hari semua titik menunjukan hasil melebihi NAB $85 \mathrm{~dB}$. Dimana rerata pengukuran pagi hari $=87,645 \mathrm{~dB}$, rerata pengukuran pada siang hari $=87,113 \mathrm{~dB}$ dan pada sore hari $=$ $87,112 \mathrm{~dB}$. Rerata pengukuran pada titik 1 sampai dengan titik 4 sudah melebihi NAB yang telah di tentukan yaitu $>85 \mathrm{~dB}$, (tabel $6)$.

Tingginya hasil pengukuran intensitas kebisingan pada UD. Ares dapat di sebabkan dari suara yang dikeluarkankan oleh mesin somil yang perawatan/pemelihraan yang kurang dilakukan oleh pemilik usaha.

Hasil pengukuran ambang dengar dari responden, paling banyak adalah responden dengan ambang dengar yang normal sebanyak 24 orang $(70,6 \%)$ dan sisanya adalah responden dengan gangguan pendengaran sebanyak 10 orang $(29,4 \%)$ termasuk dalam kategori tuli ringan.

Berdasarkan hasil pengukuran Audiogram dari 10 orang yang mengalami tuli ringan terbanyak di UD. Ares berjumlah 5 orang pekerja, dan sisanya di CV. Yudi dan CV. Gratia Magna masing-masing 4 orang pekerja dan 1 orang pekerja.

Ketulian akibat kerja dapat diidentifikasikan sebagai gangguan pendengaran pada satu atau kedua telingan, sebagian atau seluruhnya, yang timbul pada masa kerja atau sebagai akibat dari pekerjaan seseorang. Bising yang intensitasnya $85 \mathrm{~dB}$ atau lebih dapat mengakibatkan kerusakan pada reseptor pendengaran.

Gangguan pendengaran akibat bising (noise induced hearing loss) ialah ganggan yang disebabkan akibat terpajan oleh bising yang cukup keras dalam jangka waktu yang cukup lama, dan biasanya diakibatkan oleh bising dilingkungan kerja. Sifat ketulianya adalah tuli sensorineural ( persepsi ) dan pada umumnya pada kedua telinga.

Berdasarkan Penelitian yang dilakukanoleh Putri W.W, T. Martina (2016) dari hasil pengukuran intensitas kebisingan di unit produksi didapatkan hasil rata-rata kebisingan sebesar $106 \mathrm{~dB}$. Pengukuran tersebut menurut Permenakertrans No. 13/Men/X/2011 tentang Nilai Ambang Dengar Faktor Fisika dan Faktor Kimia di Tempat Kerja menyatakan bahwa pekrja tidak boleh dari 85 dB. Paparan sebesar $106 \mathrm{~dB}$ hanya diperbolehkan maksimal 3,75 menit dalam sehari. Pada kenyataannya terpapar bising lebih dari 3,75 menit dalam sehari.

Penelitian yang sama juga dilakukanoleh Kusman A, dkk yang mengadakan penelitian pada pekerja penggilingan beras didesa Situmekar, Sumedang. Dari hasil uji ratio prevalensce 
menunjukan bahwa ada hubungan antara kebisingan dengan gangguan pendengaran. Pekerja yang terpapar intensitas kebisingan $>85 \mathrm{~dB}$ mempunyai hubungan dengan gangguan pendengaran sebesar 3 kali dibanding dengan pekerja yang terpapar bising $\leq 85 \mathrm{~dB}$.

2. Hubungan Lama Kerja dengan Ambang Dengar

Hasil analisis data untuk hubungan lama kerja dengan gangguan ambang dengar dari tenaga kerja yaitu paling banyak adalah responden dengan lama kerja $<10$ tahun sebanyak 21 orang $(61,8 \%)$ yang mengalami gangguan ambang dengan sebanyak 9 orang $(26,5 \%)$ dengan kategori tuli ringan dan responden dengan pendengaran normal sebanyak 12 orang $(70,6 \%)$. Responden dengan lama kerja $>10$ tahun sebanyak 13 orang $(38,25)$ yang mengalami gangguan ambang dengar dengan keluahan tuli ringan sebanyak 1 orang $(2,9 \%)$ dan responden dengan pendengaran yang normal sebanyak 12 orang $(35,3 \%)$, (Tabel 7).

Berdasarkan hasil analisis secara statistik membuktikan terdapat hubungan yang bermakna antara lama kerja dengan ganguan ambang dengar pekerja, yang memperoleh nilai $p=0,031$, (Tabel 8).

Menurut Tarwaka (2007), faktor yang paling mempengaruhi nilai ambang dengar adalah faktor umur dan lamanya pemajanan terhadap kebisingan. Seseorang pekerja memiliki masa kerja lebih lama mungkin lebih beresiko mengalami penyakit akibat kerja dibandingkan pekerja yang memiliki masa kerja yang lebih pendek.

Hasil penelitian ini sejalan dengan penelitaian terdahulu yang dilakukan oleh Winda Wahyuni Putri dan Tri Martina (2016) dengan hasil uji korelasi memperoleh nilai $p=0,036$ berarti terdapat hubungan antara masa kerja dengan nilai ambang dengar pekerja. Diketahui pekerja dengan masa kerja < 10 tahun nilai ambang dengarnya normal sedangkan pada masa kerja > 10 tahun memiliki nilai ambang dengar yang tidak normal. Adanya hubungan masa kerja dengan penurunan nilai ambang dengar pada pekerja yang terpapar bising dikarenakan pada area kerja terdapat intensitas kebisingan yang tinggi dan mempengaruhi nilai ambang dengar pekerja sehingga mengalami ketulian. Hal ini terjadi kareana terus-menerus terpapar bising diterima oleh pekerja.

Penelitian yang sama juga dilakukan oleh Jumali, dkk, (2013) dengan judul prevalensi dan faktor resiko tuli akibat bising pada operator mesin kapal feri dari hasil uji korelasi di dapatkan hasil $p=0,016$ dimana terdapat hubungan antara masa kerja dengan nilai ambang dengar pekerja.

3. Hubungan Umur dengan Ambang Dengar

Berdasarkan hasil analisis secara statistik membuktikan bahwa tidak ada hubungan antara umur responden dengan gangguan ambang dengan, yang memperoleh nilai $p=0,745$, (Tabel 7).

Penelitian sebelumnya yang perna dilakukan antara lain pada pekerja di PT. Bangun Sarana Baja Gersik dari 32 sampel yang berumur $\leq 40$ tahun, sebanyak 15 orang yang mempunyai nilai ambang dengar normal dan sebanyak 17 orang yang mempunyai nilai ambang dengar tidak normal. Umur merupakan salah satu faktor yang dapat mempengaruhi ambang dengar. Pada usia muda kemungkinan terjadi penurunan ambang dengar akibat bising akan lebih kecil dibanding pada usia tua. Seiring bertambanya usia sreriosilia sel rambut dalam lapisan mebrana basiler koklea telinga akan terdegradasi secara alami (presbikusis). Berdasarkan hasil uji fisher exact didapatkan hasil bahwa tidak ada hubungan antara umur dengan nilai ambang dengar tenaga kerja. Artinya perubahan nilai ambang dengar akibat dari kebisingan tidak berkaitan denga umur tenaga kerja, gangguan pendengaran bisa terjadi pada usia berapapun (tidak ada kecenderungan kerentanan baik pada usia muda atau tua). Padahal menurut Siswanto (1991) pada usia 40 tahun keatas atau semakin bertambah usia akan lebih rentan mengalami gangguan pendengaran akibat kebisingan. Jadi dapat disimpulkan bahwa faktor lain selain umur yang meyebabkan tenaga kerja mempunyai ambang dengar tidak normal bisa saja disebabkan seperti kebiasaan merokok dan kebiasaan 
mengkonsumsi obat-obatan ototoksik dimana kedua hal tersebut dapat juga menyebabkan gangguan pendengaran. Karena kandungan nikotin dalam rokok serta obat-obatan ototoksik dapat menggangu kinerja dari saraf pendengaran.

Penelitian yang sama juga yang dilakukan oleh Darmawan dan Mulyono (2014) dengan judul Hubungan Karakteristik Individu dengan Nilai Ambang Dengar Pada Tenaga Kerja di PT Bangun Sarana Baja Gersik berdasarkan uji fisher exat didapatka hasil bahwa tidak ada hubungan antara umur dengan nilai ambang dengar pekerja. Artinya perubahan nilai ambang dengar akibat dari kebisingan tidak berkaitan dengan umur tenaga kerja, gangguan pendengaran bisa terjadi pada usia berapa pun.

Hasil penelitian yang dilakukan oleh Putri W.W, T. Martina (2016) tidak sejalan dengan penelitian ini dimana terdapat hubungan antara usia dengan peningkatan nilai ambang dengar pekerja sebesar $p=$ 0,621 . Adanya hubungan yang signifikan ini membuktikan bahwa presbikusis merupakan faktor yang dapat mempengaruhi nilai ambang dengar pekerja.

Menurut Tarwaka (2014) bahwa usia merupakan faktor yang tidak secara langsung mempengaruhi keluhan subjektif gangguan pendengaran namun pada usia diatas 40 tahun akan lebih mudah mengalami gangguan pendengaran dan rerntan terhadap trauma akibat bising. Penurunan daya dengar secara alamiah diasumsikan mengakibatkan peningkatan ambang pendengaran $0,5 \mathrm{~dB}(\mathrm{~A})$ tiap tahun sejak usia 40 tahun.

\section{Kesimpulan}

1. Rata-rata hasil pengukuran tingkat kebisingan pada CV Gratia dan CV Yudi memenuhi syarat $(<85 \mathrm{~dB})=83,005 \mathrm{~dB}$ dan $84,84 \mathrm{~dB}$. Rata-rata pegukuran kebisingan di UD Ares tidak memenuhi syarat $(>85 \mathrm{~dB})=$ $87,26 \mathrm{~dB}$

2. Terdapat pengaruh yang bermakna antara lama kerja dengan ganguan ambang dengar pekerja rumah kayu di Kelurahan Woloan I dan II Kota Tomohon.
3. Tidak terdapat pengaruh antara umur responden dengan gangguan ambang dengan pekerja rumah kayu di Kelurahan Woloan I dan II Kota Tomohon.

\section{Saran}

1. Bagi Perusahaan pembuatan rumah kayu sebagai bahan masukan agar dapat menyediakan alat pelindung diri berupa tutup/sumbat telinga bagi pekerja serta memperhatian kondisi mesin-mesin yang dipakai agar dapat dilakukan pemeliharaan secara berkala sehingga penyakit akibat kerja dapat dihindari.

2. Bagi Pusksemas untuk dapat memaksimalkan program Kesehatan dan keselamatan Kerja di wilaya kerja Puskesmas sehubungan dengan pengawasan/ monitoring K3 pada pekerja

\section{Daftar Pustaka}

Dermawan V, Mulyono. 2014. Hubungan Karakteristik Individu Dengan Nilai Ambang Dengar Pada Tenaga Kerja di PT. Bangun Sarana Baja Gersik. Jurnal kesehatan Lingkungan.Vol. 7. No.2 : 134139.

Darmayanto dan Suprihatin, 2013. Pengantar Pendidikan Lingkungan Hidup. Gava Media. Jakarta.

Haurissa M,P. dkk. 2014. Pengaruh Paparan Bising Terhadap Ambang Pendengaran Siswa SMK Negeri 2 Manado Jurusan Teknik Konstruksi Batu Beton. Jurnal eClinic (eCl), Vol. 2. No. 2.

Heru S, dan Haryono, 2008. Hygiene Lingkungan Kerja, Jogjakarta

Jumali,Sumadi, Andriani, dkk. 2013. Prevalensi dan Faktor Risiko Tuli Akibat Bising pada Operator Mesin Kapal Feri. Jurnal Kesehatan Masyarakat Nasional. Vol.7, No. 12 :545-550.

Kusman A,dkk. 2016. Hubungan Antara Kebisingan dengan Gangguan Pendengaran Pada Pekerja Penggilingan Beras.

Lumonang N.P, dkk. 2015. Hubungan Bising dan Fungsi Pendengaran pada Teknisi Mesin Kapal yang Bersandar di Pelabuhan Bitung. Jurnal e-Biomedik (eBm). Vol.3, No.3 : 728-732. 
JKL Volume 9 No. 1 April 2019

Peraturan Menteri Tenaga Kerja dan transmigrasi Republik Indonesia Nomor PER.13/MEN/X/2011 tentang Nilai Ambang Batas Faktor Fisika dan Faktor Kimia di Tempat Kerja, Jakarta.

Putri W.W, T.Martiana. 2016. Hubungan Usia dan Masa Kerja Dengan Nilai Ambang Dengar Pekerja Yang Terpapar Bising di PT. Sidoarjo. The Indonesia Journal of Occupational Safety and Health. Vol.5. No.2 :173-182.

Siswanto.1991. Kebisingan dan Alat Pelindung Diri. Balai Hiperkes dan Keselamatan Kerja. Jawa Timur
Mamesah, dkk. Intensitas Bising dan Ambang Dengar,

Tarwaka, dkk. 2004. Ergonomi untuk Keselamatan Kesehatan Kerja dan Produktivitas. Surakarta: UNIBA Press.

Tarwaka. 2014. Kesehatan dan Keselamatan Kerja; Manajemen dan Implementasi K3 di Tempat Kerja. Surakarta: Harapan Pres.

Tjan, H. dkk. 2013. Efek Bising Mesin Elektronika Terhadap Gangguan Fungsi Pendengaran Pada Pekerja di Kecamatan Sario Kota Manado, Sulawesi Utara.. Journal Biomedik.Vol.1 No. 1 : 134- 139. 